\title{
RECENSIONES
}

\section{John HIGGS. Historia alternativa del siglo XX. Más extraño de lo que cabe imaginar. Madrid, Taurus, 2015, 353 páginas, por Luis Castro Berrojo.}

En una conferencia de 1936 H. G. Wells recordaba cómo hasta 1909 o 1910, "el mundo vivía en un estado de confianza, valores compartidos y estable seguridad que ahora nos resulta casi increíble. No teníamos entonces la menor sospecha de hasta qué punto esta seguridad aparente estaba siendo socavada por la ciencia, la innovación y la investigación". Para evitar que las novedades, sobre todo de tipo científico y técnico, escaparan al conocimiento del "ciudadano medio educado", Wells proponía la elaboración de una "Enciclopedia mundial", en continua actualización y revisión crítica, que estuviera al alcance de todos y que incluyera la historia así como "una imagen exacta y razonablemente precisa de nuestro universo" a través del conjunto de las ciencias. Si no fuera porque Wells concibe tal obra como volúmenes impresos, se podría decir que su idea se corresponde con la actual Wikipedia. (H. G. Wells, World Brain, cap. 1)

Pues bien, el libro que comentamos parte de una actitud intelectual semejante a la de Wells: busca identificar y analizar con gran aliento divulgativo los elementos culturales clave del siglo xx que, según el autor, se revelaron como algo "verdaderamente nuevo, inesperado y radical". Fenómenos tanto más sorprendentes cuanto que, por un lado, hacia 1900 no faltaban científicos -como Newcomb o lord Kelvin- para quienes las ciencias tenían poco camino por recorrer, pues habrían logrado ya una codificación casi completa del universo; y porque, además, la mayoría de los avances científicos del siglo xx no iban a ir ya por la senda recta del racionalismo y del positivismo anteriores, sino por caminos tortuosos de incertidumbre, relativismo y paradojas.

Entre esos elementos nuevos estarían la teoría de la relatividad, la guerra total y la desaparición de los imperios, el sicoanálisis, el principio de incertidumbre, la carrera espacial y armamentista de la Guerra fría, la liberación de la mujer, la teoría del caos, las corporaciones transnacionales, el postmodernismo e internet, a los que dedica sendos capítulos. Hay también un interesante apartado sobre lo que Higgs llama el "modernismo" literario y artístico. Pero tropezamos aquí con una confusión semántica, no aclarada por el traductor, cuya labor es más bien deficiente. (Llega a confundir latitud y longitud geográfica en pág. 24). Pues el autor no nos va a hablar de Gaudí, el Arts \& Crafts, Rubén Darío, Klimt o Debussy, sino de Le Corbusier, Picasso, Joyce, Sartre, Beckett o Stockhausen, usando la etiqueta "modernismo" para caracterizar casi todos las tendencias artísticas del siglo XX, lo cual es manifiestamente simplista. (Por cierto que los primeros autores citados brillan por su ausencia y el 
modernismo artístico propiamente dicho -el Art nouveau, Modern style o Art déco- ni siquiera se menciona).

Como se ve, no se trata propiamente de una "historia del siglo xx", sino, como reza su título en inglés, de "Una Interpretación del siglo xx" (Making Sense of the Twentieth Century), partiendo de algunas ideas básicas que ayuden a entender los cambios mentales, actitudinales y estéticos del siglo xx y los episodios más convulsos de este. No solo no es un libro de historia, sino que su principal limitación es una contextualización demasiado superficial y de brocha gorda, de modo que, por ejemplo, Hitler y Stalin, así como los estados que crearon, se presentan como "muy similares" (pág. 90); el estado del bienestar se define como "punto medio" entre el capitalismo y el comunismo de la URSS y de China (pág. 233); y se dice que la visión de los ecologistas cambió "de modo radical gracias a las fotos del programa Apolo" (pág. 273).

Más allá de esas limitaciones, el libro es un ensayo de estilo ágil y gran capacidad didáctica. Es notable el uso de analogías, símiles sorprendentes y generalizaciones que ayudan a entender fenómenos o teorías complejos. Por ejemplo, en los primeros capítulos echa mano del ónfalos como símbolo central de referencia que enmarca el universo cultural de las civilizaciones mientras se mantienen estables (y que es distinto en cada una de ellas). Algo que sustenta una visión del mundo y del orden social compartida por las sociedades en su conjunto y que en un momento dado entra en crisis para dar paso al relativismo y la pluralidad ideológica. Higgs sostiene que ese mundo mental, originado en las civilizaciones de la Antigüedad, aún se mantenía aparentemente sólido a principios de siglo XX, cuando, como percibieron Wells y otros, todo empezó a cambiar.

Por extensión y analogía, el campo semántico del ónfalos comprendería, por ejemplo, el observatorio de Greenwich como centro definidor de las coordenadas del espacio-tiempo decimonónico, hasta que la teoría de la relatividad viene a erosionarlo con una inusual idea de lo que es la materia, la energía y el espacio y tiempo en que se mueven. Del mismo modo, el mundo del poder imperial/monárquico -ampliamente predominante hacia 1900 y basado en el tradicionalismo eclesiástico y la jerarquía social- cae durante la Gran guerra y es sustituido tendencialmente por la sociedad democrática de masas. El arte "realista" o "naturalista" decimonónico es barrido por las múltiples perspectivas del surrealismo, el cubismo y la "corriente de conciencia", entre otras; la física newtoniana y el racionalismo cartesiano, en fin, son trascendidos por teorías de un universo en expansión trufado de agujeros negros y de un mundo subatómico donde reinan el "principio de incertidumbre" y los "universos paralelos", y donde el punto de vista del observador determina el resultado de la observación.

Esas generalizaciones y analogías recorren todo el libro y contribuyen a una lectura entretenida y sugestiva. Pero ello implica casi inevitablemente una visión demasiado esquemática y no siempre sólida intelectualmente. En este sentido, y sin irnos a niveles de alta divulgación científica (como la de la serie Drakontos de editorial Crítica), si queremos hacernos una idea de los principales adelantos científico-técnicos de las últimas décadas, sacaríamos mejor provecho de libros como el de Bill Bryson (Una breve historia de casi todo. Barcelona, RBA, 2004) o el de Marcus Chown (El universo en tu bolsillo. Del gen al cosmos: un científico acaba explicándotelo todo. Barcelona, RBA, 2015). O, si se trata de contextualizar mejor los cambios literarios y artísticos, iríamos a obras como la de Daniel J. Boorstin (Los creadores, Barcelona, Crítica, 1994) o de Donald Sasoon (Cultura. El patrimonio común de los europeos. 
Barcelona, Crítica, 2006), sin olvidar el clásico de T. S. Kuhn para comprender los cambios de paradigmas científicos (La estructura de las revoluciones científicas, México, FCE, 1962).

No carece tampoco esta obra de perfiles críticos. En particular pone en el punto de mira fenómenos como el individualismo extremo, que relaciona ideológicamente con autores como Aleister Crowley, Ayn Rand o algunos artistas de la Beat generation; a los científicos alentadores de una carrera espacial como plataforma para lograr un first strike nuclear que pudiera aniquilar la URSS (se cita a Von Braun y a Von Neumann; podríamos añadir a H. Kahn y a E. Teller); denuncia las grandes corporaciones, "máquinas de hacer dinero inmorales" que con su afán productivista y crematístico ponen en peligro los equilibrios ecológicos del Planeta y generan una creciente desigualdad social; y señala el consumismo desaforado, en buena medida inducido por una publicidad invasiva. Frente a estas amenazas el autor cree ver signos de un nuevo sentido de responsabilidad y de comunitarismo que se abrirían paso a través de movimientos sociales y puntos de resistencia basados en las redes de comunicación. Pero la obra tampoco va demasiado lejos en este ámbito, donde se echa de menos la perspectiva internacional y la referencia a los países menos desarrollados y a los conflictos interétnicos o interculturales.

A pesar de todo, el mérito principal de esta obra radicaría en su carácter sintético, su enfoque original y la consideración de fenómenos de la cultura de masas no siempre atendidos por otro tipo de obras más "serias". Nos referimos a temas como el cine de Hollywood, la ciencia ficción y la literatura y la música pop desde los años sesenta en adelante. 